Results Of 39 patients (29 male, 10 female), mode of transmission was 27(69\%) sexual, 11(28\%) vertical, and 1 unknown. The vertically-acquired cohort have lower CD4 counts (64\% vs 93\% CD4 >350), more resistance mutations (including triple class resistance) and lower rates of viral suppression (45\% vs 90\%) compared to the sexually-acquired cohort. Retention in care is also lower, ( $72 \%$ vs $92 \%$ attending in the last year). STI rates are high overall but higher in the sexual transmission cohort, $75 \%$ vs $55 \%$.

Discussion/conclusion The under 25 HIV clinic cohort comprises 2 distinct groups: a vertically -acquired cohort with poorer outcomes, who consistently require more support and motivation to remain engaged in care; and a sexually-acquired cohort who adhere to HAART, but have higher rates of STIs and would benefit from support involving motivational interviewing and health promotion.

\section{P137 TACKLING HIV RELATED STIGMA AND DISCRIMINATION WITHIN NHSGGC SERVICES}

Shivani Karanwal, Nicky Coia*, John Barber, Louise Carroll. NHS Greater Glasgow and Clyde, Glasgow, UK

\subsection{6/sextrans-2015-052126.180}

Background/introduction Individuals with HIV report experiencing stigma and discrimination. Outcome 5 of the Scottish Government Sexual Health and BBV Strategy (2011-15) aims to address this issue. Locally a system was established to record and collate events on a 'third party' basis, which revealed that most incidents occurred within NHS services.

Aim(s)/objectives In collaboration with the HIV Patient Forum, we examined HIV stigma among NHSGGC staff by:

- Assessing knowledge of HIV

- Measuring HIV attitudes and beliefs

- Capturing staff experiences of HIV stigma

Based on the findings, we are developing an appropriate staff CPD programme.

Methods Between 8-23 July 2013, an anonymous self-complete questionnaire was sent to all 38,000 NHSGGC employees. This was circulated by email from the Director of Public Health with reminders issued via internal staff bulletins.

Results A $10 \%$ completion rate was achieved $(\mathrm{n}=3,971$ responses). Staff

- had variable knowledge of HIV which was much poorer in relation to treatment advances and routes of transmission.

- held mixed attitudes with less favourable attitudes correlated to poor knowledge

- reported practice which could be perceived as discriminating against patients

- expressed a strong desire for greater knowledge and access to training

Discussion/conclusion This survey from the largest UK NHS employer provides evidence that poor knowledge and attitudes are based on outdated information and assumptions which in turn leads to poor patient experiences. This has provided a platform to develop pro-active anti-stigma approaches ranging from a staff-facing campaign, refreshed HIV training and development of a patient empowerment toolkit.

\section{P138 CASH DIRECT: INCREASING PATIENT CHOICE AND ACCESS TO LARC}

Jane Marshall*, Amanda Taylor. St Helens and Knowsley Teaching Hospitals NHS Trust, St Helens, Merseyside, UK

\subsection{6/sextrans-2015-052126.181}

Background/introduction Busy lifestyles and women's continued need and desire for reliable methods of contraception, has led to the development of 'CaSH Direct' which offers LARC assessments and procedures at times that are convenient to women but without the need for multiple visits to.

Aim(s)/objectives CaSH Direct aims to:

- Increase women's access to LARC

- Reduce demand on clinics

- Increase women's choices of times and location of procedure

- Reduce the time women spend in clinic

- Make more efficient use of staff time

Methods Women attending clinic and requesting a LARC are offered a telephone consultation at a time that is convenient to them (day or evening) meaning women do not need to take time away from work or family to access the service avoiding the need to wait in clinic to be assessed. Clients are then contacted by a sexual health practitioner who completes an assessment over the phone allowing the woman to take the call in an environment that is familiar to her and without the cost or time implication of attending clinic. A suitable appointment time is made at the end of the assessment for the client to attend an agreed clinic for the procedure to be carried out.

Results Client feedback has proved to be favourable for the service with $70 \%$ rating the service as excellent, pressure in walk-in clinics has been eased and appointment times are being utilised more effectively.

Discussion/conclusion CaSH Direct has made a positive impact on service provision and client choice through innovative and effective use of skills within the service.

\section{P139 TO ATTEND OR NOT TO ATTEND - "WHY" IS THE QUESTION?}

Dianne Neal, Oluseyi Hotonu*. Morpeth Clinic, Northumberland, UK

10.1136/sextrans-2015-052126.182

Background/introduction Documents such as "10 high impact changes for genitourinary medicine $48 \mathrm{~h}$ access" produced by the Department of Health (DH) in 2006 have helped reduce waiting times and increase capacity. Our service experienced a significant increase in the rate of non-attendance of appointments following a change in service base in February 2014. In response we decided to ascertain whether adopting some or all of the DH's high impact changes would improve the poor attendance.

Aim(s)/objectives On review we were already employing most of the recommended changes. One omission was high impact change 5: "Review current access system and make it easier for patients to access the service", therefore we asked patients their preferred means of attendance (appointment or drop in) and times of attendance.

Methods 105 services users were questioned over a 4 week period from the 1st until the 31st August 2014. 